\title{
Carbon Nanotube Mask Filters and their Hydrophobic Barrier and Hyperthermic Antiviral Effects on SARS-CoV-2
}

\author{
Sangsu Lee†, Jeong-Seok Nam†, Jiye Han $\dagger$, Qiang Zhang†, Esko I. Kauppinen†*, Il Jeon†* \\ $\dagger$ : Department of Chemistry Education, Graduate School of Chemical Materials, Crystal bank \\ Institute, Pusan National University, 63-2 Busandaehak-ro, Busan 46241, Republic of Korea; \\ Department of Nano Fusion Technology, Pusan National University, 63-2 Busandaehak-ro, \\ Busan 46241, Republic of Korea \\ ¥: Department of Applied Physics, Aalto University School of Science, Aalto FI-00076, Finland \\ * corresponding author
}

E-mail: il.jeon@spc.oxon.org (I.J.), esko.kauppinen@aalto.fi (E.K.)

1. Structural composition of the SMS filter of the face mask

2. CNT film production

3. Durability of SMS filter and CNT

4. SEM images of the SMS filter

5. Photographic image of the CNT filter-attached black mask

6. Anti-viral test

7. Human coronavirus OC43 sampling image

8. SEM images of human coronavirus $\mathrm{OC} 43$

9. TEM images of human coronavirus $\mathrm{OC} 43$ 
1. Structural composition of the SMS filter of the face mask

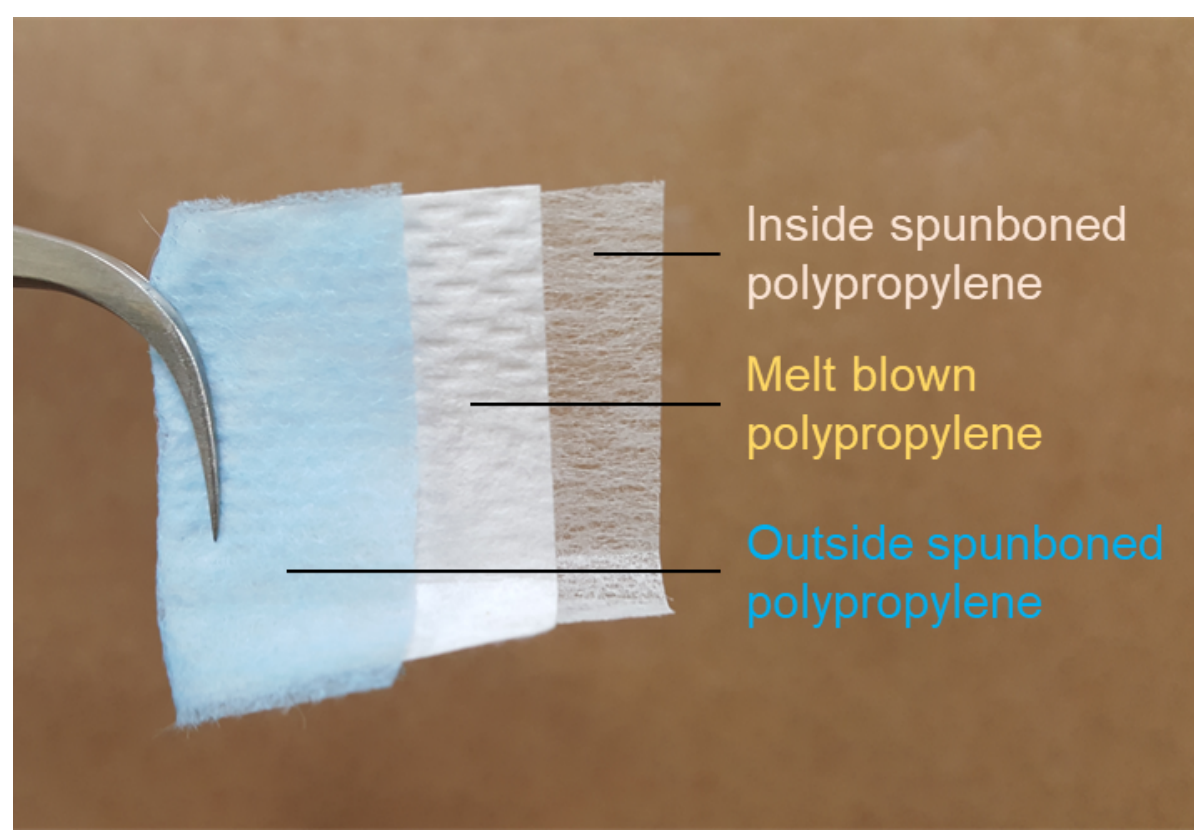

Figure S1. Structural composition of the SMS filter of the dental mask. 


\section{CNT Film Production}

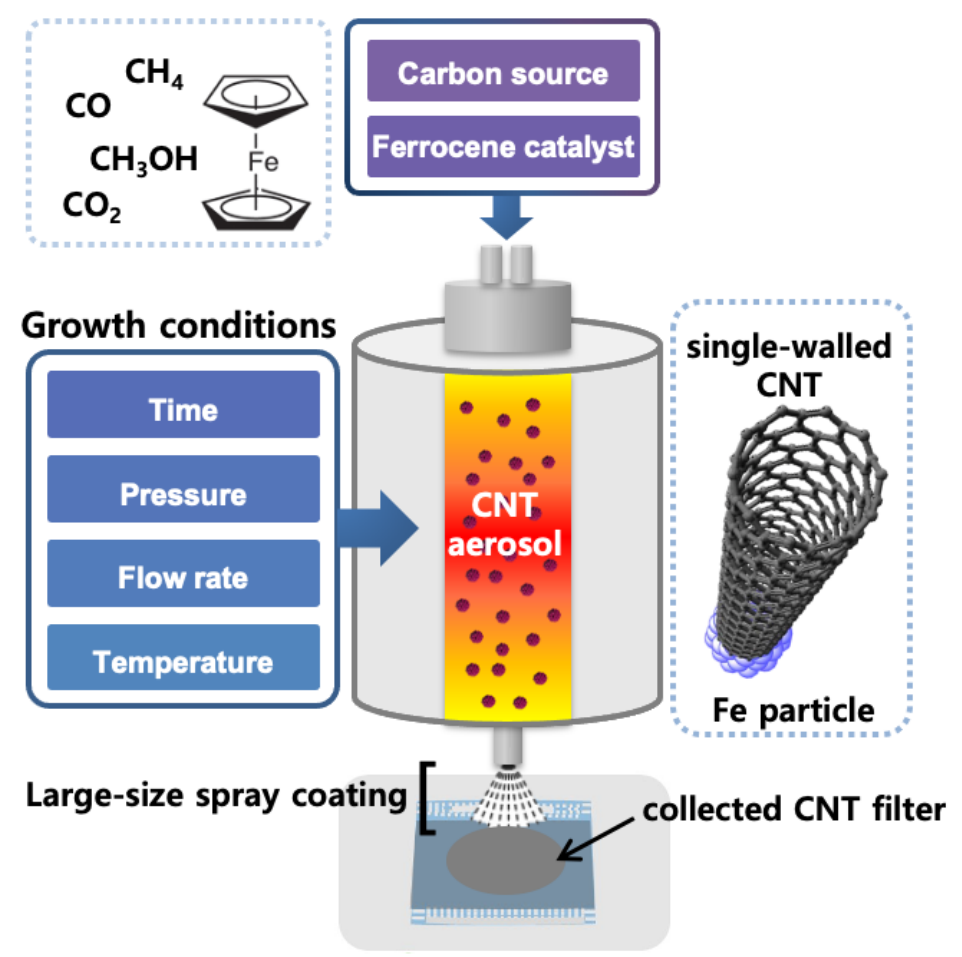

Figure S2a. Graphical illustration of aerosol-synthesized chemical vapor deposition (CVD).

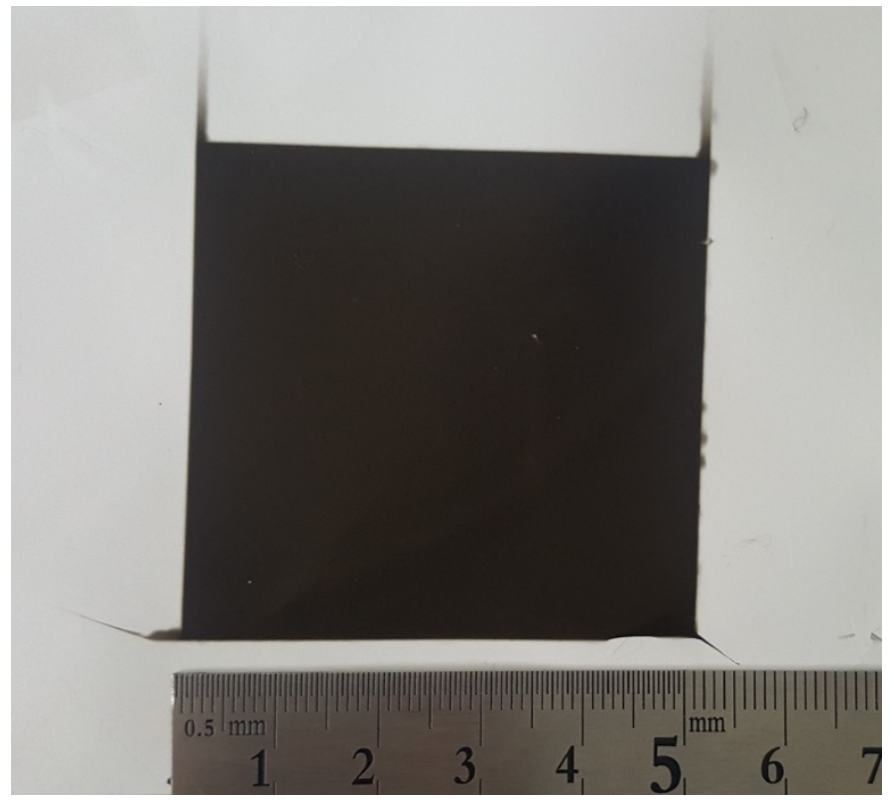

Figure S2b. Photographic image of the large-size D-CNT using the aerosol-synthesized CVD. 


\section{Durability of SMS filter and CNT}

Table S1. The contact angle table to check durability of filters for 5 days as well as after heat sterilization.

\begin{tabular}{|c|c|c|c|c|c}
\hline \multirow{2}{*}{ filter } & \multicolumn{5}{|c}{ contact angle } \\
\cline { 2 - 6 } & Day1 $\left(^{\circ}\right)$ & Day2 $\left({ }^{\circ}\right)$ & Day3 $\left(^{\circ}\right)$ & Day4 $\left(^{\circ}\right)$ & $\mathbf{7 0}{ }^{\circ} \mathbf{C}, \mathbf{1 5}$ min \\
\hline CNT & $131.8 \pm 3.8$ & $133.3 \pm 3.6$ & $132.5 \pm 3.4$ & $133.3 \pm 3.6$ & $132.2 \pm 2.9$ \\
\hline SMS & $125.4 \pm 3.2$ & $122.1 \pm 3.8$ & $120.9 \pm 4.0$ & $117.3 \pm 10.4$ & $104.9 \pm 5.5$ \\
\hline
\end{tabular}
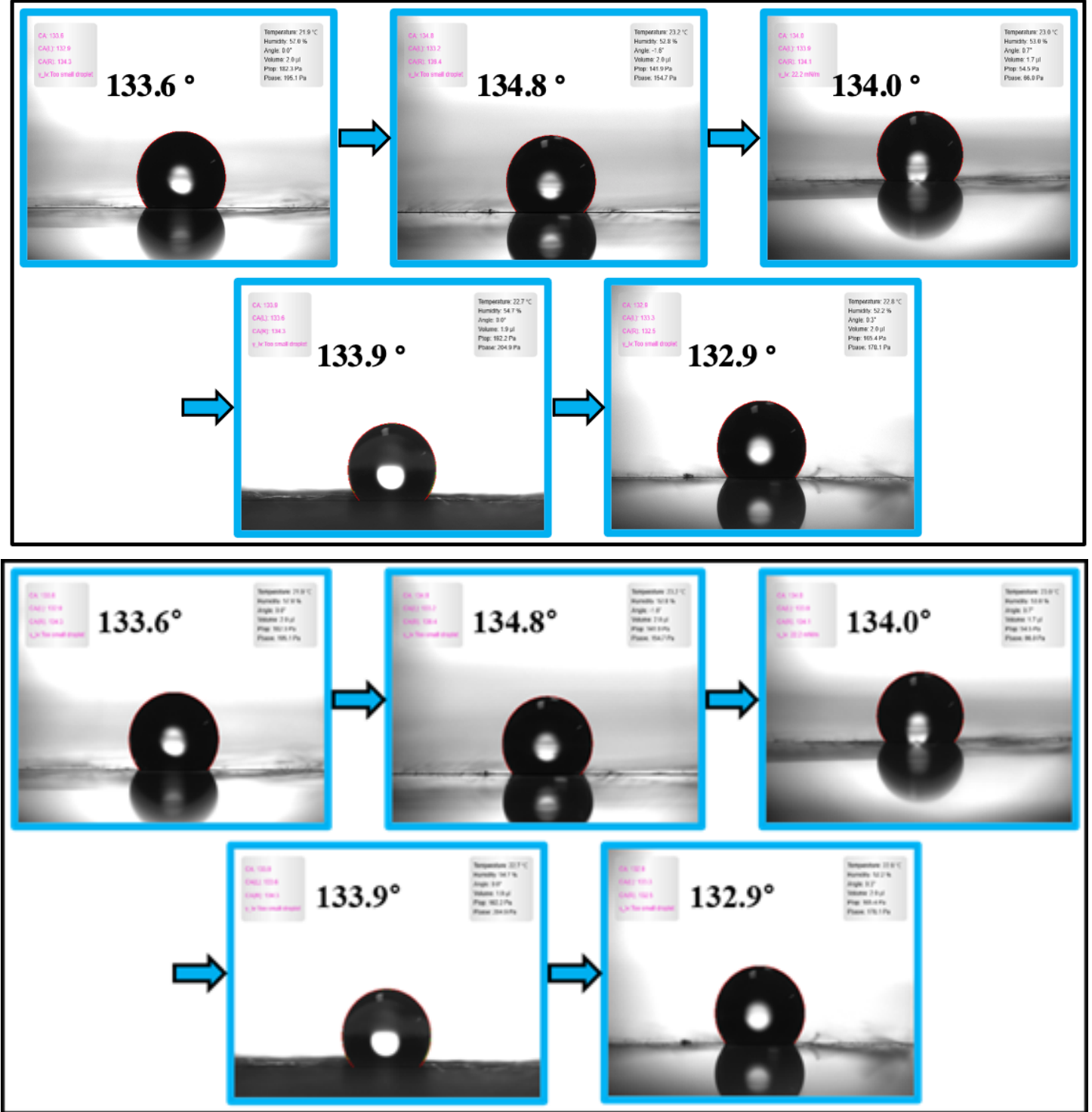

Figure S3a. Photographic images of the water droplets on CNT demonstrating the durability of the CNT filter. 

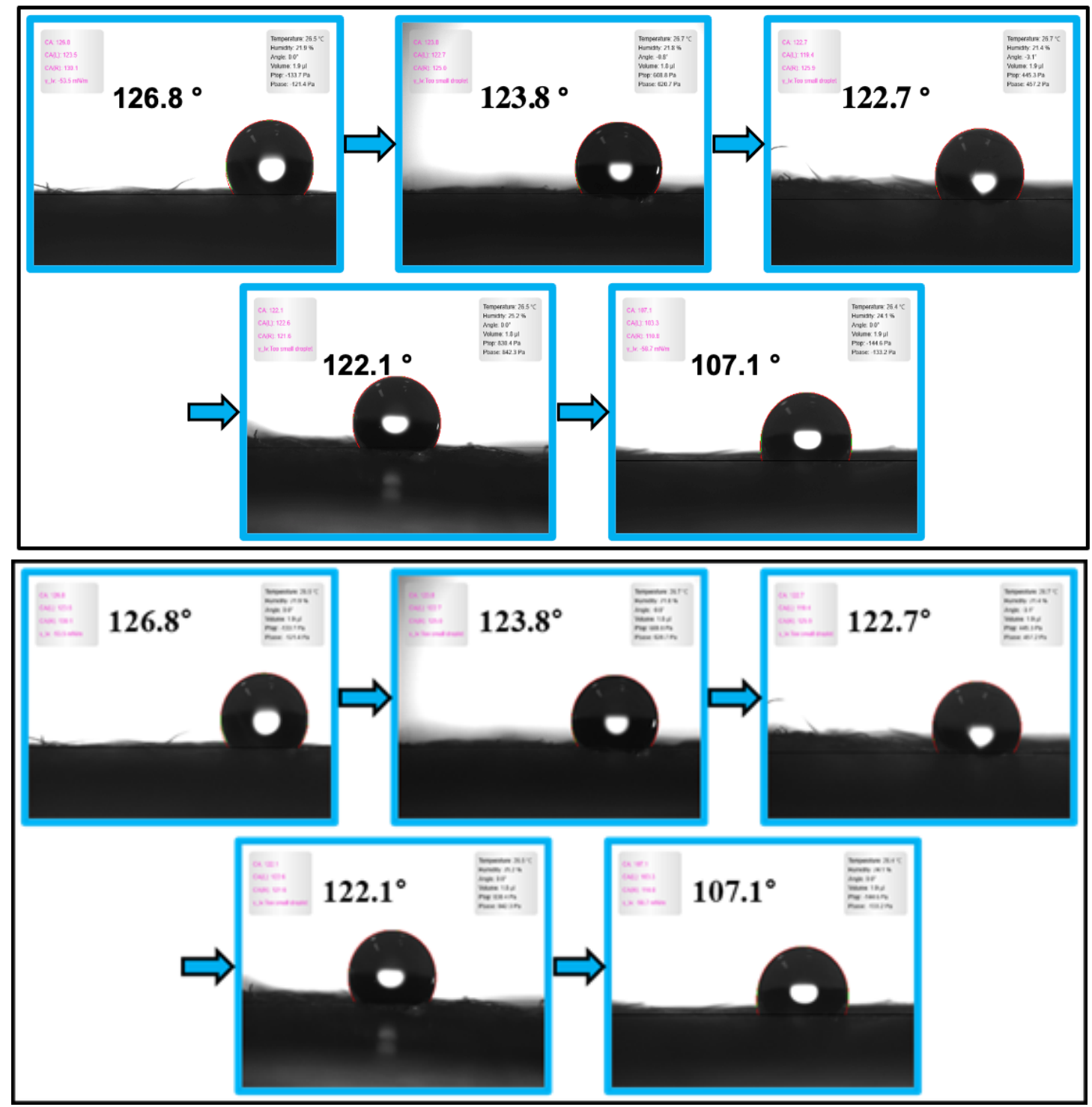

Figure S3b. Photographic images of the water droplets on SMS filter over $4 \mathrm{~d}$.

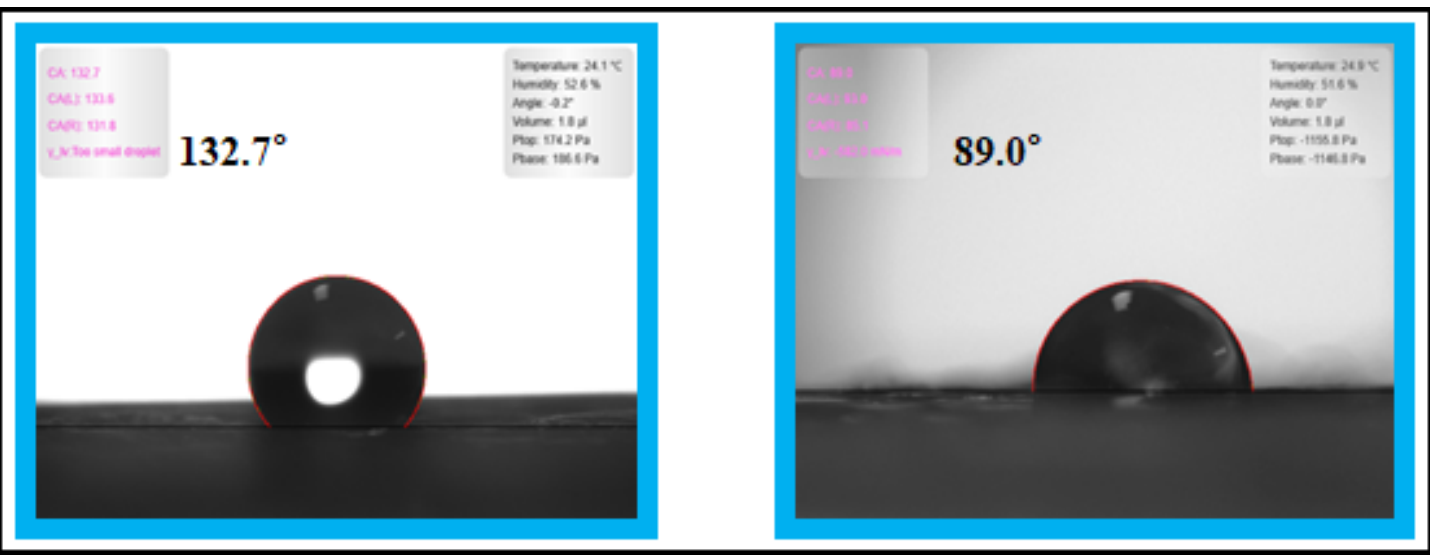

Figure S3c. Comparison of the contact angles of a relatively new CNT and a few years old CNT. It is indicated that oxidation of CNT takes place over a long term and the hydrophobic effect of the CNT filter is semipermanent. 
a)

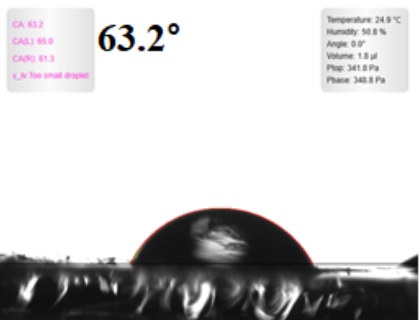

b)

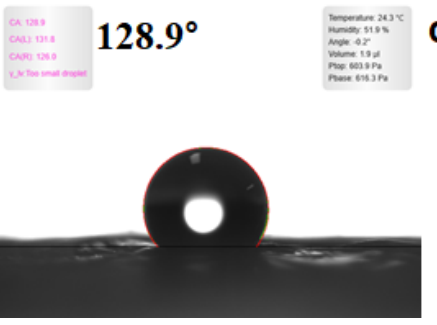

c)

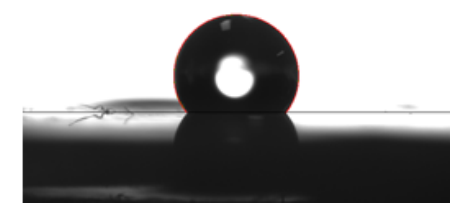

Figure S4. Measured value of water contact angle by substrate a) glass, b) plastic, and c) SMS filter. 


\section{SEM images of the SMS filter}
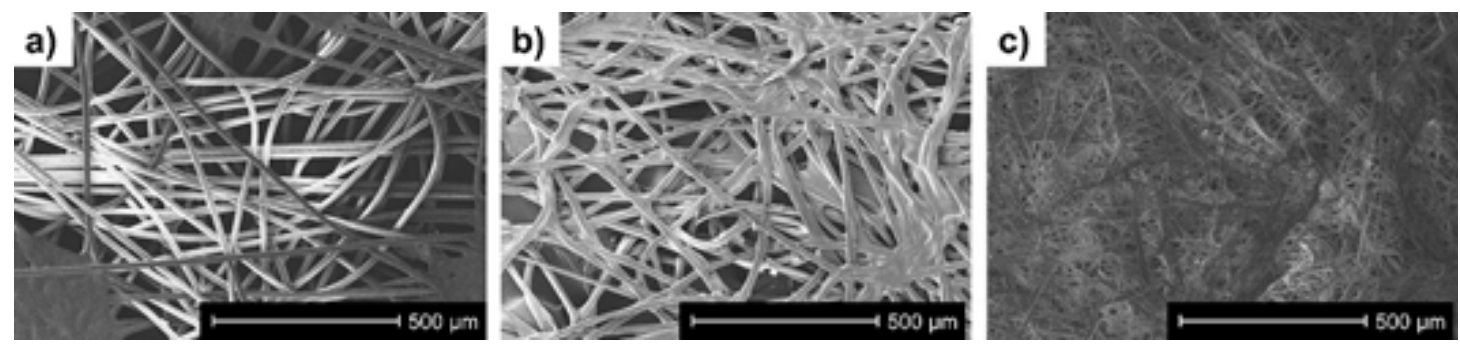

Figure S5. Top view SEM images of the SMS filter separately. The images of a) a top spunbonded polypropylene layer, b) a bottom spunbonded polypropylene layer, and c) a melt blown polypropylene layer. 


\section{Photographic Image of the CNT Filter-attached Black Mask}

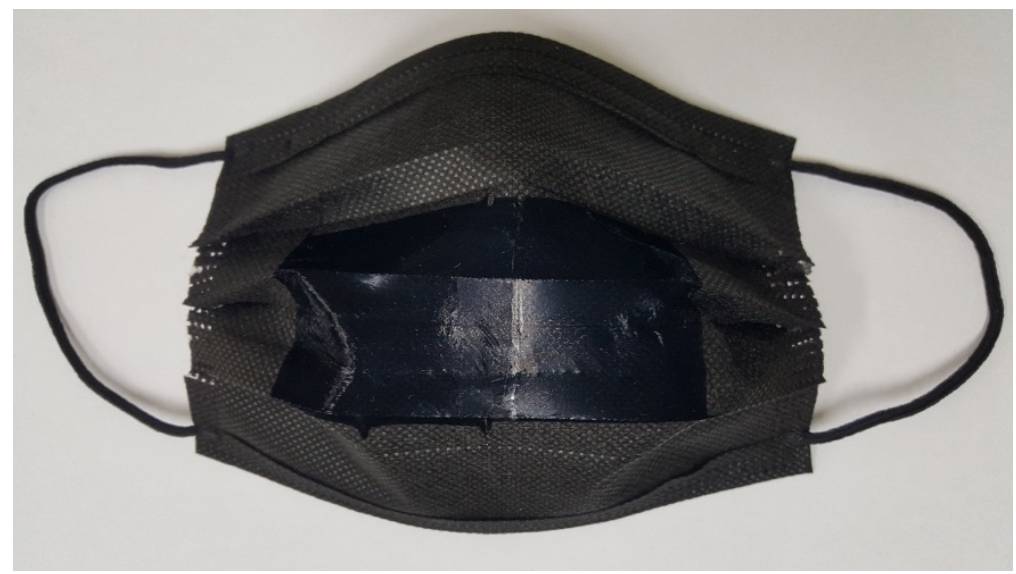

Figure S6. Images of the D-CNT filter-laminated black mask used in the hyperthermic antiviral effects test.

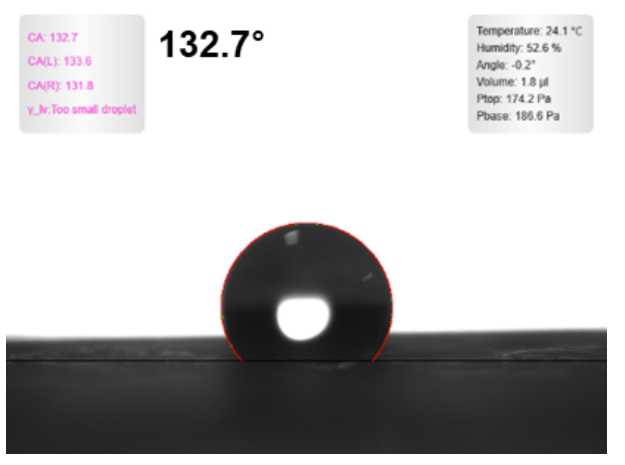

The average contact angle value was $131.4^{\circ}$ which is almost the same as the water contact angle of the CNT filters with lighter density $\left(131.7^{\circ}\right)$ used in Figure $2 \mathrm{~b}$ and Figure $4 b-d$.

Figure S7. Water contact angle measured on D-CNT. 


\section{Anti-viral Test}

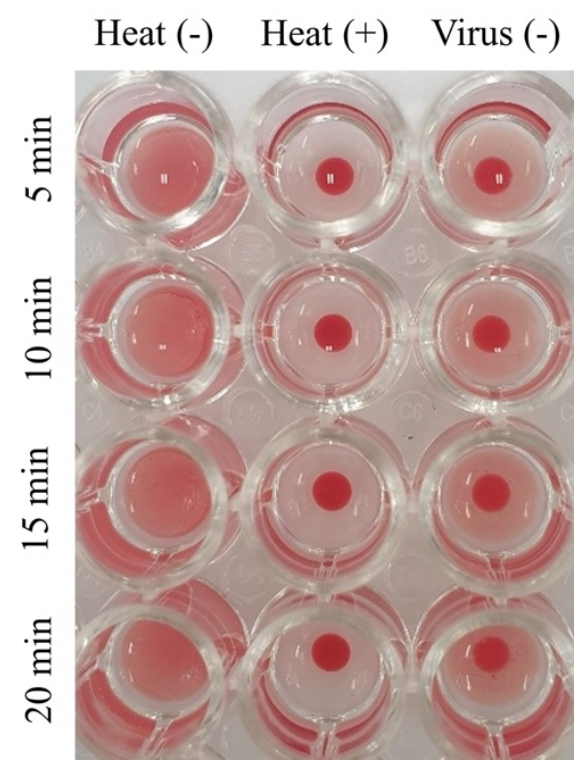

Figure S8. The result image of the HA assay. The active virus with hemagglutinin binds to erythrocyte and agglutinate and it is expressed red and cloudy. In case of inactive virus, it does not agglutinate and blood cells deposit and form red spots. The image shows that all of the virus was completely inactivated due to the heat treatment at $65^{\circ} \mathrm{C}$, as the result of the heat treatment sample and the virus-free group were identical. 
7. HCoV-OC43 sampling Image

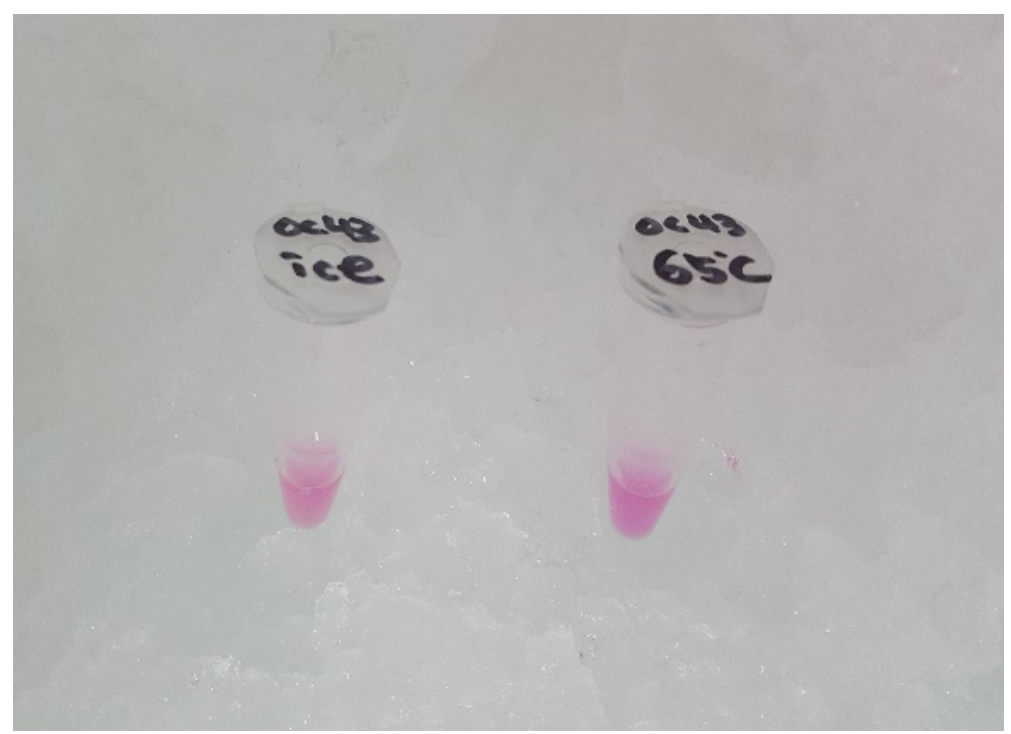

Figure S9. Images of the untreated (left) and heat-treated (right) HCoV-OC43 samples for SEM and TEM measurements. 


\section{SEM images of human coronavirus $\mathrm{OC43}$}
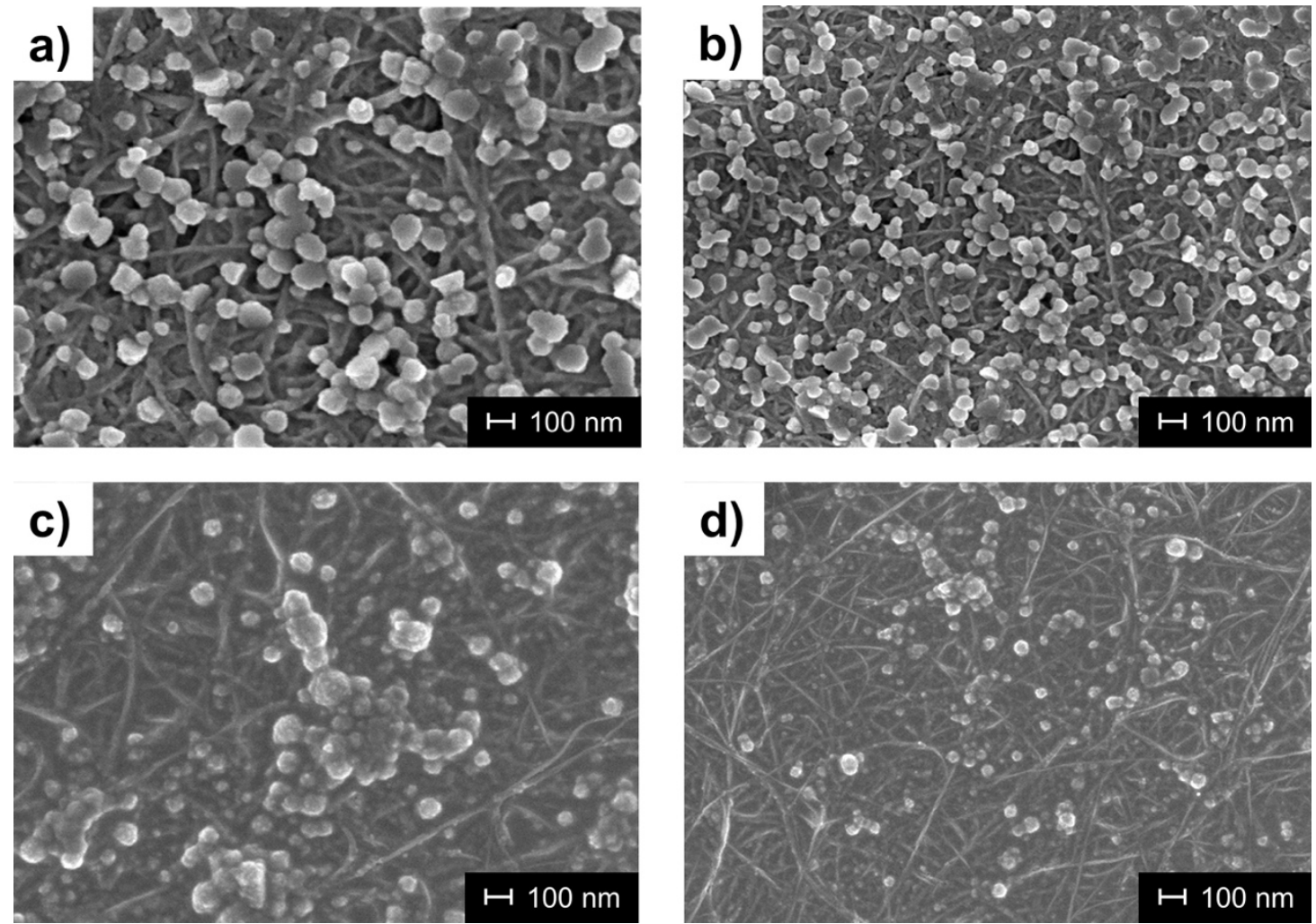

Figure S10. SEM images of $\mathrm{a}-\mathrm{b}$ ) untreated and $\mathrm{c}-\mathrm{d}$ ) heat treated virus at $65{ }^{\circ} \mathrm{C}$ throughout 5 mins on the aerosol-synthesized carbon nanotube. 


\section{TEM images of human coronavirus $\mathrm{OC} 43$}
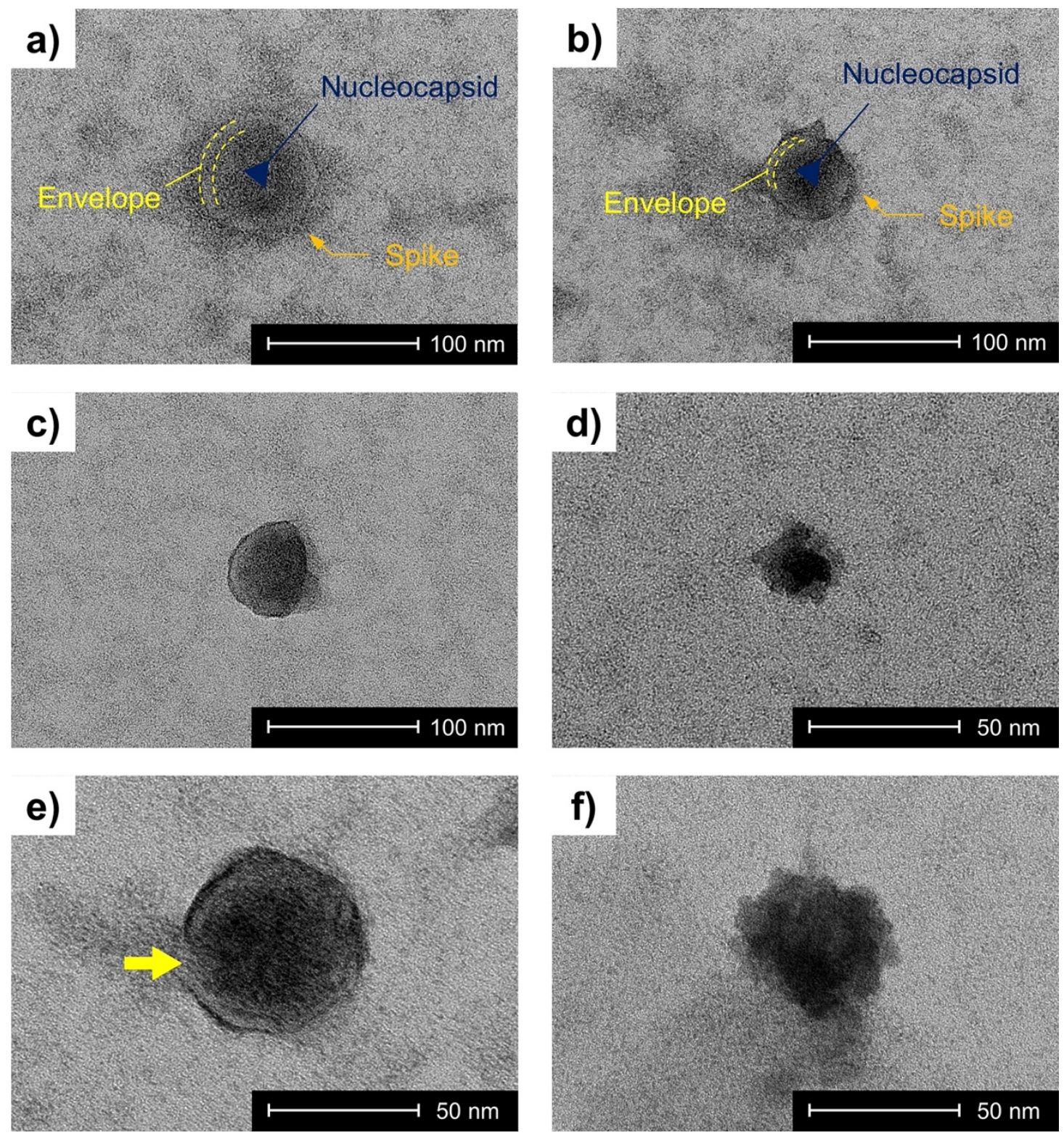

Figure S11. TEM images of $\mathrm{a}-\mathrm{b}$ ) untreated and $\mathrm{c}-\mathrm{f}$ ) heat treated virus at $65{ }^{\circ} \mathrm{C}$ throughout 5 mins. While the nucleocapsid, envelop and spike of a virus are clearly seen from untreated virus, denaturing of the envelope (Figure $5 \mathrm{~g}$ ) and shrunk exterior (Figure S8) of the viruses after the heat treatment are seen from heat treated virus images. 